\title{
ESTADO PUNITIVO E CRIMINALIZAÇÃO DA POBREZA: DO DESMEMBRAMENTO SOCIOESPACIAL À SEGREGAÇÃO CARCERÁRIA
}

\author{
PUNITIVE STATUS AND CRIMINALIZATION OF POVERTY: \\ FROM SOCIO-SPACE BREAKDOWN TO PRISON SEGREGATION
}

\author{
Evandro da Silva Gomes Filho e Francisco Ercílio Mourab
}

Centro Universitário Doutor Leão Sampaioa,b Mestrado MASS/UECE; líder do grupo de pesquisa: Direitos Humanos e Globalização e membro do CEP Unileãob

\section{RESUMO}

O presente artigo visa abordar as questões relacionadas às práticas punitivas típicas das instituições estatais que caracterizam o Estado Punitivo que atua na repressão das massas pobres dos bairros periféricos do espaço urbano em nossas metrópoles. Propõe-se ainda, a analise acerca da população brasileira carcerária e sua semelhança com a população mais desprovida de recursos materiais no país. Tal estado de coisas, próprias de políticas segregacionistas das classes mais pobres, ocorrem em assentamentos urbanos cujos territoriais se caracterizam por dificuldades de acessos aos serviços urbanos básicos, ao mesmo tempo em que são incessantemente vigiados pelos aparatos estatais de repressão e controle monitorados pelas forças policiais e o INFOPEN; desta forma infere-se que a população no cárcere brasileiro é análoga àquela que é segregada nos espaços urbanos, sendo que ambas as populações possuem em comuns traços característicos referentes a um baixo índice de escolaridade, situação de pobreza, cor preta ou parda. Portanto, as políticas de controle do espaço interurbanos nacional pelas nossas elites privilegiam a formação destes espaços urbanos, através de mecanismos que utilizam o controle econômico do mercado imobiliário; e controles ideológico e político desses sectores sociais subalternos de nossa sociedade.

Palavras-chave: Estado Punitivo. Segregação Socioespacial. Criminalização da Pobreza. Sistema Carcerário.

\section{ABSTRACT}

This article aims to address issues related to punitive practices typical of state institutions that characterize the Punitive State that acts in the repression of the poor masses in the peripheral neighborhoods of the urban space in our metropolises. It is also proposed to analyze the Brazilian prison population and its similarity with the population most deprived of material resources in the country. Such a state of affairs, typical of the segregationist policies of the poorer classes. they occur in urban settlements whose territories are characterized by difficulties in accessing basic urban services, at the same time they are incessantly watched by the state apparatus of repression and control monitored by INFOPEN; thus, it is inferred that the population in Brazilian prison is analogous to that which is segregated in urban spaces, with both populations having in common characteristic traits related to a low level of education, poverty, black or brown color. Therefore, the national interurban space control policies by our elites privilege the formation of these urban spaces, through mechanisms that use the economic control of the real estate market, ideological and political controls of these subaltern social sectors of our society.

Keyword: Punitive State. Socio-spatial segregation. Criminalization of Poverty. Prison system. 


\section{V.10 N.1 (2022) ISSN: 2317-434X}

\section{INTRODUÇÃO}

A presente pesquisa pretende analisar as questões entre o Estado Punitivo atualmente em curso no nosso país, a segregação socioespacial dos espaços urbanos e a segregação do cárcere no brasil. Procura-se reflexionar de que forma o Estado Brasileiro atua no sistema de punição e na segregação do território urbano e os seus desdobramentos no sistema carcerário; ademais compreender a gestão da miséria do ente estatal punitivo nesse contexto caracterizado por um permanente estado de coisas inconstitucionais ${ }^{1}$.

A predileção desta temática aparece no tempo em que ocorre a expansão e consolidação do Estado Punitivo em nosso território, que decorre principalmente em períodos cronológicos caracterizados pela adoção de políticas macroeconômicas de cunho neoliberal, a través da adoção de discursos conservadores, cujo foco acentua a predileção das elites no controle das ações relacionadas com a segurança pública da sociedade, principalmente nas áreas urbanas de maior densidade populacional das capitais dos estados no Brasil, tal expansão dar lugar a processos sociais que se desdobram, via de regra, em manifestações políticas e seus impactos nas mídias sociais, atribuídas às parcelas empobrecidas da população civil e que comprometem o funcionamento do sistema jurídico e carcerário.

Constata-se que no Brasil o processo político da redemocratização trouxe a implementação do modelo econômico neoliberal, no bojo das políticas anunciadas pelo consenso de Washington ${ }^{2}$, ao tempo em que se intensifica, cada vez mais, a segregação socioespacial, criando uma maior homogeneidade social em espaços urbanos mais específicos gerando disparidades nas ofertas de serviço público e privado nessas regiões, dando lugar a desigualdades no acesso aos serviços públicos básicos, em relação a outras localidades e zonas urbanas habitadas pelas classes medias altas e ricas de nossa sociedade. Ante o exposto, com a crescente segregação urbana, incita-se o aumento na criação de medidas de controle e monitoramento das regiões periféricas pobres pelas forças de segurança do estado, v.g. as UPP's cariocas,

${ }^{1}$ Estado de coisas inconstitucional é a situação na qual estão presentes violações generalizadas, contínuas e sistemáticas de direitos humanos fundamentais, por vários órgãos estatais, demandando soluções estruturais igualmente amplas, para a solução dos problemas e supressão das omissões e violações estatais.

${ }^{2} \mathrm{O}$ Consenso de Washington foi a forma como ficou popularmente reconhecido um encontro ocorrido em 1989, na militarizando a vida cotidiana dessas populações.

Leciona Flávio Villlaça em sua obra Espaço intraurbano no Brasil (2001, p. 142), ao afirmar que, no que se refere à distribuição da população nas cidades brasileiras, o espaço urbano brasileiro estruturou-se pela lógica da segregação socioeconômica do espaço intraurbano. De acordo com o autor (2001, p. 142), essa lógica consiste em um "processo segundo o qual, diferentes classes ou camadas sociais tendem a se concentrar cada vez mais em diferentes regiões suburbanas, ou conjuntos de bairros da metrópole". Para Villaça (2001, p. 142) a construção do espaço urbano por meio da segregação socioespacial implica na dominação social, política e econômica por meio do espaço urbano, portanto das contradições sociais expressadas pela luta de classes.

Em tempos tão sombrios e de políticas super autoritárias e liberais, deve se observar a postura do ente estatal na garantia dos direitos inerentes a sociedade e na criação de uma narrativa de segregações e exclusões, que se início com a exclusão dos pobres carentes de liberdade civis, com reflexos na segregação dos pobres no cárcere, evidenciando uma arbitrariedade e seletividade nos cuidados dos marginalizados pelo sistema capitalista no Brasil, através do modelo punitivo/excludente, responsável pela extensão da marginalidade e da exclusão de sectores sociais de renda média e baixa de nossa sociedade, aprofundando as desigualdades sociais no pais.

Neste sentido, é translúcida a aplicação do direito penal como um dos principais instrumentos de coerção social do poder estatal na tutela desses bens jurídicos selecionados pelo legislador e como limitador do acesso aos direitos consagrados pela lei maior aos sectores sociais subalternos entre as populações pobres, aos quais se negam $o$ acesso as modalidades comunitárias de propriedade e dos seus próprios meios de produção, entre os quais destacamos o direito à moradia adequada. O que é padrão de vida adequado? Qual é o padrão mínimo para que um ser humano viva com dignidade? Existem muitas necessidades a serem preenchidas para que se tenha uma vida digna. No entanto, há pelo menos condições básicas que precisam ser atendidas para que as pessoas possam

capital dos Estados Unidos. Nesse encontro, realizou-se uma série de recomendações visando ao desenvolvimento e à ampliação do neoliberalismo nos países da América Latina. Essa reunião foi convocada pelo Institute for International Economics, sob o nome de "Latin Americ Adjustment: Howe Much has Happened?", e envolveu instituições e economistas de perfil neoliberal, além de alguns pensadores e administradores de países latino-americanos. 


\section{V.10 N.1 (2022) ISSN: $2317-434 X$}

sobreviver. São elas: alimentação adequada, saúde e moradia. $^{3}$

Ampliando esse pensamento, Coelho (2015, p.13) afirma que o direito penal:

Possibilita ao Estado intervir legitimamente sobre a liberdade individual dos cidadãos, quando estes violem a proteção que as normas penais dão aos bens jurídicos. Mas também limita as possibilidades da intervenção estatal, ao vincular e condicionar a legitimidade de tal intervenção, a parâmetros restritivos de legalidade.

Teóricos da criminologia ampliam ainda mais esse viés de análise, apontando como principal função do direito penal o controle social de uma classe sob a outra. $O$ direito penal opera visando manter a ordem econômica e social vigente, sendo, portanto, instrumento de dominação em uma sociedade estruturada em classes. Logo, não possui (conforme versa a doutrina penal clássica) a função de combater o crime e proporcionar o bem viver na vida em sociedade. Zaffaroni e Pierangeli (2004, p.68) alcançam semelhante conclusão, entendendo o direito penal como controle social institucionalizado em forma e discurso punitivo, sustentando uma estrutura de poder social pela via punitiva. Seus estudos apontam também a seletividade como estruturante do sistema penal:

[...] em que pese o discurso jurídico, o sistema penal se dirige quase sempre contra certas pessoas mais que contra certas ações. Não se pode ignorar que fazem parte do sistema penal [...] os procedimentos contravencionais de controle de setores marginalizados da população, as faculdades sancionatórias policiais arbitrárias, as penas sem processo, as execuções sem processo etc. (ZAFFARONI; PIERANGELI, 2004, p.69).

\section{METODOLOGIA}

A pesquisa é de natureza qualitativa, pois a análise é feita através de consultas a textos doutrinários, artigos, e-book, jurisprudências e legislações. Dessa maneira, serão coletados dados seguros e verídicos para que possamos analisar o desmembramento espacial e a segregação social que são causados pelo estado punitivo e pela criminalização carcerária.

Segundo Vergara (2009, p. 42), a pesquisa qualitativa "é realizada em áreas na qual há pouco conhecimento acumulado e sistematizado. Por sua natureza de sondagem, não comporta hipóteses que, todavia, poderão surgir durante ou ao final da pesquisa".

Gil (2008, p. 28) afirma que "as pesquisas deste tipo têm como objetivo primordial a descrição das características de determinada população ou fenômeno ou estabelecimento de relações entre variáveis". Dessa maneira, o presente projeto caracteriza-se por ser uma pesquisa descritiva, pois tem o intuito de descrever acerca do desmembramento espacial e a segregação social.

Além disso, trata de um estudo bibliográfico que objetiva mostrar o conhecimento de determinados doutrinadores, acerca do tema, utilizando seus escritos e documentos. "Do ponto de vista do método, a pesquisa seguirá a lógica indutivo-dedutiva, pois fará induções a partir das representações dos sujeitos-objetos, bem como deduções das normas existentes.” (MENEZES, 2008, p.7).

No presente trabalho serão utilizados autores como Débora Regina Pastana, Rodrigo Ghiringhelli de Azevedo, LenioStreck, dentre outros.

Após o levantamento de diversos pensamentos doutrinários divergentes, o texto buscará alcançar resultados e soluções para o desmembramento espacial e a segregação social que são causados pelo estado punitivo e pela criminalização carcerária.

\section{ESTADO PUNITIVO E SEUS DESDOBRAMENTOS}

A escolha desta temática surge no período em que se demonstra a expansão e a consolidação do Estado Punitivo no mundo global, principalmente no Brasil.

Portanto, para Débora Regina Pastana (2007, P. 30), apesar da relativa abundância de pesquisas retratando a violência criminal e seus temas correlatos, não se destaca no Brasil, como objeto específico de reflexão, o real significado das atuais posturas políticas sobre a punição. Os trabalhos relativos à segurança pública produzidos atualmente preocupam-se em discutir a eficácia ou, na maioria das vezes, a ineficácia das instituições de controle. No entanto, mostra-se oportuno, nesse momento obsessivo por segurança, questionar o que há de simbólico nas políticas penais atuais, para em grande medida associá-las ao projeto liberal em curso no país.

Para que haja uma maior compreensão do que gera uma política criminal reservada a um caráter "punitivo" pode se utilizar a perspectiva de Garland (1999, p.60) que poderá justificar a trajetória da sociedade como punitiva. 


\section{V.10 N.1 (2022) ISSN: $2317-434 X$}

A resposta é mais complexa do que parece. A "punitividade", de fato, em parte é um juízo comparativo acerca da "severidade" das penas com relação às medidas penais precedentes, em parte depende dos objetivos e das justificativas das medidas penais, assim como também da maneira pela qual a medida é apresentada ao público. As novas medidas que aumentam o nível das penas, reduzem os tratamentos penitenciários, ou impõem condições mais restritivas aos delinquentes colocados em liberdade condicional ou vigiada [...] podem ser consideradas "punitivas", pois aumentam com relação a um ponto de referência anterior.

Destarte, a maior parte das medidas penais recentes, adotam a continua necessidade de punição severa, traduzindo o sentimento público de insegurança e incitando objetivos punitivos ou denunciadores atestando, ao mesmo tempo, seu caráter inequivocamente "punitivo".

Isso significa dizer que também no Brasil o "Estado providência" sucumbe frente ao "Estado punitivo", no qual a assistência social dá lugar à atuação policial e carcerária. Esse novo paradigma altera a imagem das classes populares carentes de políticas sociais e as configura como inaptas, quando não como simples parasitas do Estado (SALLA; GAUTO; ALVAREZ, 2006, p. 334). Segundo Wacquant (2001) essa transição entre o que ele denomina de "Estado Providência para o EstadoPenitência" destina-se "[...] aos miseráveis, aos inúteis e aos insubordinados à ordem econômica e étnica que se segue ao abandono do compromisso fordista-keynesiano e à crise do gueto."

Com a introdução das políticas neoliberais econômicas e sociais em que se prega o Estado Mínimo, em que se realiza a privatização dos bens e patrimônio estatal, a redução dos gastos com políticas públicas sociais, a precarização das leis trabalhistas e previdenciárias, entre outras políticas que enxugam o estado, desta forma se agrava a situação social das massas de marginalizados e despossuídos pelo capitalismo, por consequência de um Estado mínimo que opera em todas as áreas sociais e econômicas, relegando as questões sociais, ao novo padrão de organização estatal e societário ao modelo de "Estado neoliberal", dando lugar a um estado forte apenas para a gestão das questões penais. É o que Loïc Wacquant (2003) denominou "Estado-centauro", ao analisar a questão penal norte-americana.

[...] esse Estado-centauro, guiado por uma cabeça liberal, montada num corpo autoritário, aplica a doutrina do laissez-faire a montande, em relação às desigualdades sociais, aos mecanismos que as geram (o livre jogo do capital, desrespeito do direito do trabalho e desregulamentação do emprego, retração ou remoção das proteções coletivas), mas mostra-se brutalmente paternalista e punitivo a jusante, quando se trata de administrar suas consequências a nível cotidiano. [...] a redução do setor do bem-estar social do Estado e o concomitante incremento do seu braço penal são funcionalmente articulados, como se fossem os dois lados da mesma moeda da ação reestruturado do Estado nas regiões mais afastadas do espaço social e urbano, na era do neoliberalismo em ascensão. (WACQUANT, 2003, p.88-89).

Nessa nova lógica punitiva da administração da miséria no neoliberalismo, dois principais mecanismos são utilizados segundo o autor. O primeiro é um maior controle do comportamento das classes subalternas marginalizadas, gerando maior atenção dos aparatos de controle do Estado em seus bairros segregados: "o comportamento dos cidadãos despossuídos e dependentes deve ser acompanhado de perto e sempre, que necessário, corrigido por meio de rigorosos protocolos de vigilância, prevenção e sanção" (WACQUANT, 2003, p.112). Em um segundo momento, ocorre à maior criminalização, por meio de mudanças legislativas e do modus operandi dos aparatos de controle, gerando o hiper encarceramento das classes ditas perigosas. Uma máquina estatal que vigia, pune e segrega seletivamente os indesejáveis da cidade. Versa Wacquant (2003, p.115),

[...] o repentino crescimento da prisão está relacionado ao colapso do gueto urbano como recipiente físico de corpos escuros indesejáveis. Aqui queremos simplesmente observar que um importante motor por detrás do crescimento carcerário nos Estados Unidos foi a "guerra às drogas" - política cujo nome não é adequado, uma vez que designa, na realidade, uma guerra de guerrilha à (sic.) perseguição penal aos traficantes das calçadas e aos consumidores pobres - dirigida primordialmente contra os jovens das áreas urbanas centrais decadentes, para quem o comércio de narcóticos no varejo fornecia a fonte mais acessível e confiável de emprego lucrativo no recuo duplo do mercado de trabalho e do Estado de bem-estar.

Ocorre, portanto, uma dupla segregação, que inicialmente confina os pobres em seus bairros decadentes e precários, altamente vigiados pelos aparatos de controle estatal, e, em um segundo momento, no sistema carcerário. O chamado controle do crime, cuja função primordial é o controle das classes ditas perigosas, desembocando no hiper encarceramento dos marginalizados por meio da criminalização da pobreza. Garland (2008) oferece 


\section{V.10 N.1 (2022) ISSN: $2317-434 X$}

enormes contribuições para o entendimento da loucura punitiva aqui operante, para o teórico houve uma grande virada de mesa epistemológica, os ideais modernos de ressocialização do delinquente desapareceram, substituídos pela imagem do delinquente como marginal inveterado, inimigo da sociedade e impossível de ser reabilitado.

Em análises mais recentes Pastana (2019, p.84-85) entende que a evolução do Estado Punitivo no Brasil continua em ritmo acelerado:

[...] esse modelo de Estado, cada vez mais cristalizado em alguns países, como o exemplar caso brasileiro, está ancorado em diversas políticas públicas, voltadas para o aumento do controle, desde a mais simples contenção das interações sociais, como as repressões policiais às manifestações de rua, até o mais alto grau de punição simbólica, e por isso mesmo exemplar, aos selecionados desviantes, materializadas já no âmbito da Justiça Penal. É aqui que o crescimento da população prisional coloca-se; ou seja, como expressão máxima da atuação simbólica do direito penal. O poder legislativo também tem papel fundamental nesse processo, alimentando o sistema punitivo de novas leis incriminadoras, que reforçam a punição por meio do aumento de pena trazido muitas vezes em tempo maior de encarceramento para diversos delitos.

Conquanto, para Pastana (2019) o Estado Punitivo é imbricado de várias dimensões. Entre elas, nota-se a gestão penal atuarial, no qual o aumento punitivo das políticas de segurança do Estado é justificado na lógica da gerência dos riscos de delinquência das classes ditas perigosas. Além disso, é notável o populismo penal.

\section{DIREITO PENAL: "LA LEY ES COMO LA} SERPIENTE; SOLO PICA A LOS DESCALZOS”.

Tem-se por entendimento já consolidado na doutrina jurídica/penal hodierna de que o direito penalista tem como basilar função operacionalizar os mecanismos repressivos e sofisticar os instrumentos de poder/controle Estatal, como instrumento de tutela de bens jurídicos selecionados pelo legislador e como regulador da intervenção penal estatal. Segundo Nucci (2014, p.52), o direito penal

[...] ocupa dos mais graves conflitos existentes, devendo ser utilizado como a última opção do legislador para fazer valer as regras legalmente impostas a toda comunidade, utilizando-se da pena como meio de sanção, bem como servindo igualmente para impor limites à atuação punitiva estatal, evitando abusos e intromissões indevidas na esfera de liberdade individual.

O direito penal tem por precípuo escopo garantir e manter a ordem econômica e social vigentes, neste caso, sendo uma espécie de mecanismo de dominação em uma sociedade estruturada em classes.

Um fundamental e importante estudo que proporcionam dados acerca dos usos do direito penal foi realizado por LenioStreck (2012), que analisou diacronicamente a evolução do direito penal nacional e, o Decreto-Lei n. 2.848 de 1940, concluiu que "la ley es como la serpiente; solo pica a los descalzos". Alusão à seletividade do sistema penal nacional, que escolhe entre sua clientela os mais pobres, os moribundos, os descalços.

Para o autor, "a preocupação maior sempre foi com a proteção da propriedade privada e dos interesses lato sensu das camadas dominantes, [...] o Código Penal apontou efetivamente para o 'andar de baixo', [...] sempre dando ênfase à propriedade privada" (STRECK, 2012 p.8).

Em sua pesquisa, para comprovar tais análises em referência as preferências legislativas penais para a proteção do bem jurídico/patrimonial, em relação ao bem jurídico/vida humana, restando demonstrado o cunho patrimonialista, classista e criminalizante da pobreza através das escolhas legislativas, o autor realiza comparações entre os tipos penais e suas sanções.

De forma cristalina, trazendo à tona estudo do autor, abordaremos acerca de sua análise, comparando algumas sanções conferidas aos crimes contra o patrimônio e algumas outras aos crimes contra a pessoa.

Um exemplo translúcido e intrigante sobre esta temática está nos crimes contra o patrimônio, onde se encontram positivados do artigo 155 ao artigo 180-A no Código Penal Brasileiro de 1940, integrando os tipos penais que compõem a parte especial do referido código. Dos artigos 121 ao 154-A do Código Penal Brasileiro são previstas as sanções impostas aos praticantes de crimes contra a pessoa.

Ao ser comparado as penas abstratas da tipificação criminal de homicídio simples (artigo 121 do CP), com pena de reclusão de 6 a 20 anos, e do crime de roubo qualificado por lesão corporal grave (artigo 157, § $3^{\circ}$, inciso I do CP), com pena de reclusão, de 7 a 18 anos, e multa, nota-se que a pena mínima conferida ao crime de homicídio simples é menor que a positivada para o crime 


\section{V.10 N.1 (2022) ISSN: $2317-434 X$}

de roubo qualificado por lesão corporal grave. E quando compararmos a pena do crime de homicídio qualificado (artigo 121, $\S 2^{\circ}$ do CP), com pena de reclusão, de 12 a 30 anos, com a pena do crime de roubo qualificado pelo resultado morte (artigo 175, $\S 3^{\circ}$, inciso II do CP), reclusão, de 20 a 30 anos e multa, nota-se que a pena mínima abstrata conferida ao crime de roubo qualificado pelo resultado é superior a pena de homicídio qualificado.

É notável tal discrepância jurídica, uma vez que, mesmo com a inclusão da lei 13964/2019, (pacote anticrime), que alterou o código penal e outras leis penais, que teve como um dos intuitos o agravamento das penalidades de diversas condutas criminais, foi omisso neste ponto, explana Streck (2019, p.9):

[...] à "qualificadora" de "subtração de coisa alheia móvel" no crime de homicídio (ou, se assim se quiser, homicídio praticado com o motivo de obtenção de vantagem patrimonial), comina-se uma pena abstrata no mínimo 8 (oito) anos mais grave do que a pena prevista à prática de homicídio qualificada por emprego de meio tortura ou outro meio cruel ou ainda na ocorrência de qualquer das circunstâncias qualificadoras previstas (v.g.: mediante paga ou promessa de recompensa) no artigo 121, § 2o, do Código Penal.

Ademais, outra temática importante que se retira desta questão é que o crime de latrocínio, ou seja, o homicídio praticado com a finalidade de qualquer obtenção patrimonial, não é de competência do tribunal do júri, pelo simples fato de ser considerado crime contra o patrimônio e não contra a vida, mesmo ocorrendo o óbito de uma pessoa, sendo notória a contradição e omissão legislativa.

Por conseguinte, o crime de furto qualificado (artigo $155, \S 4^{\circ}$ do $\mathrm{CP}$ ), pena de reclusão de 2 a 8 anos e multa, comparado ao crime de lesão corporal de natureza grave (artigo $129, \S 1^{\circ}$ do $\mathrm{CP}$ ), reclusão de 1 a 5 anos, possui pena mínima e máxima abstrata superior ao crime de lesão corporal de natureza grave, mais uma vez, denotando a preferência punitiva do legislador no que concerne os crimes contra o patrimônio em relação aos crimes contra a pessoa. Complementemos:

A subtração de bem patrimonial do interior da residência da vítima realizada por mais de uma pessoa ou com abuso de confiança (veja-se que, nesse último caso, pode-se enquadrar a subtração de objetos da residência por empregado da residência/estabelecimento) implica sanção superior à ofensa à integridade corporal de que resulte debilidade permanente de membro, sentido ou função, ou ainda que coloque em perigo a vida da vítima (STRECK, 2012, p.9).

Ainda no citado estudo de Lenio Streck, o mesmo analisa as diferenças no tratamento dos crimes patrimoniais e os ditos crimes de "colarinho branco que abrange os crimes contra a ordem econômica, cometidos por pessoas de alto capital social que utilizam de sua influência e relações, inclusive com as autoridades do Estado, para cometer um extenso rol de delitos que vão desde o pagamento de propinas, aos favorecimentos ilícitos, até ao uso de subornos e fraudes. São crimes que atingem as estruturas de produção, circulação e consumo de riquezas, afetando os interesses difusos e coletivos de toda a população. Desses crimes, muitos se encontram positivados na lei 7.492/86.

Por lógica, inclusive por aquela punitivista, tais crimes deveriam ter alta quantidade de pena abstrata, dado o caráter amplo das violações, não atingindo apenas a um indivíduo, como na maioria dos tipos penais, mas a toda a sociedade. Entretanto, como já foi exposto, o direito penal pátrio é seletivo e não tem como escopo punir as classes abastadas economicamente, e sendo os cometedores desses crimes oriundos delas, o direito penal garantiu artimanhas para que esses sujeitos não fossem punidos à semelhança daqueles provenientes das classes pobres.

Como exemplo significativo de tal problemática pode-se citar os crimes de sonegação fiscal e contra a ordem tributária, que têm extinta sua punibilidade se o tributo é pago antes do recebimento da denúncia. Ainda acerca do modus operandi do judiciário no tratamento extremamente desmedido entre os crimes de sonegação e contra a ordem tributária e os crimes patrimoniais, Lenio Streck (2012, p.15) lembra que:

[...] em exemplo que também põe a lume a clientela do direito penal no Brasil, enquanto o Tribunal de Justiça do Rio Grande do Sul decidiu que o furto de objetos avaliados em R $\$ 37,00$ (trinta e sete reais) não é insignificante, o Tribunal Regional Federal da Quarta Região (que compreende o Estado do Rio Grande do Sul) pacificou jurisprudência no sentido de que é bagatelar, para fins criminais, a sonegação de R\$ 2.500,00 (dois mil e quinhentos reais) em tributos para o crime de descaminho. (STRECK, 2012, p.15).

No tópico a seguir, trataremos do que se denominou Estado Punitivo em escala urbanística, o, que em muito influencia nossa análise até o momento, visto que, os territórios marginalizados urbanos tornam-se o locus de atenção dos aparelhos de controle do Estado, 


\section{V.10 N.1 (2022) ISSN: $2317-434 X$}

tornando-se territórios cada vez mais monitorados com justificativas pautadas em políticas de segurança pública que não evidenciam suas reais intenções: a exclusão e o controle das classes populares.

\section{COMUNIDADE CINGIDA: O ESTADO PUNITIVO EM ESCALA URBANA}

O Brasil se apresenta atualmente como uma das nações com as maiores cidades do mundo. Após intenso processo de êxodo rural nas últimas décadas o país sofreu intenso processo de urbanização.

Segundo os dados históricos de pesquisas do Instituto Brasileiro de Geografia e Estatísticas (IBGE) o processo de urbanização nacional, nota-se o aumento exorbitante de aproximadamente $31 \%$ de população urbana nos anos quarenta para aproximadamente $85 \%$ de pessoas habitando terras urbanas nos anos 2010.

Constata-se com esses dados que a maioria dos brasileiros habitam hoje espaços considerados cidades com maiores ou menores graus de adensamento e serviços considerados tipicamente urbanos.

O Instituto Brasileiro de Geografia e Estatísticas em uma produção científica apresentado como Áreas urbanizadas do Brasil ano 2015, utiliza-se do conceito de "manchas urbanas" para a identificação das áreas urbanizadas, tais manchas são visíveis via satélite e demonstram o conjunto de áreas construídas que se adensam. Neste tema, José Afonso da Silva em um dos clássicos sobre Direito Urbanístico Brasileiro, conceitua:

[...] um centro populacional assume características de cidade quando possui dois elementos essenciais: a) as unidades edilícias - ou seja, o conjunto de edificações em que os membros da coletividade moram ou desenvolvem suas atividades produtivas, comerciais, industriais ou intelectuais; b) os equipamentos públicos - ou seja, os bens públicos e sociais criados para servir às unidades edilícias e destinados a satisfação das necessidades de que os habitantes não podem prover-se diretamente e por sua própria conta (estradas, ruas, praças, parques, jardins, canalização subterrânea, escolas, igrejas, hospitais, mercados, praças de esportes, etc) (SILVA, 2010, p.26).

Como já demonstrado, uma das perspectivas de atividades do Estado Punitivo é sobre o espaço urbano, especificamente sobre a ótica dos territórios habitados pelas classes mais carentes. Espaços que só recebem do Estado atenções no campo de sua ação punitiva e quase nunca em forma de estrutura social urbana de qualidade e quantidade de serviços públicos para esta parcela populacional.

Denota-se desde o início de nossa reflexão, que a atuação do Estado na seara socioespacial, como instituição pública estruturante das cidades brasileiras, tornou-se cada vez mais segregadora e com menos inclusão.

No Brasil, as classes mais pobres se encontram segregadas e em constante vigilância pelos aparatos estatais de controle, principalmente em comunidades carentes, tendo que arcar em seu cotidiano com a violência de uma força policial inapta que age em repetidas ocasiões em desconformidade com a legalidade e em aberto abuso de autoridade.

\section{Wacquant (2001, p.9) afirma que a violência policial brasileira}

[...] inscreve-se em uma tradição multissecular de controle dos miseráveis pela força, tradição oriunda da escravidão e dos conflitos agrários, que se viu fortalecida por duas décadas de ditadura militar, quando a luta contra a "subversão interna" se disfarçou em repressão aos delinquentes. Ela apoia-se numa concepção hierárquica e paternalista da cidadania, fundada na oposição cultural entre feras e doutores, os "selvagens" e os "cultos", que tende a assimilar marginais, trabalhadores e criminosos, de modo que a manutenção da ordem de classe e a manutenção da ordem pública se confundem.

Exemplo notório de como o Estado Punitivo age na segregação e criminalização da pobreza, encontra-se nas políticas públicas das (UPPs), as denominadas Unidades de Polícia Pacificadora, localizadas em grande parte das comunidades suburbanas da cidade do Rio de Janeiro.

Acontece que por meio destas unidades de controle do estado, periferias inteiras se tornaram corriqueiramente sitiadas e vigiadas pelo poder estatal, além de estarem sob o constante arbítrio das forças estatais e grupos armados não estatais, conhecidos nas periferias urbanas como "milicias". O que, conforme Pastana (2019, p.183), demonstra a intenção dessa política pública: “a segregação dos miseráveis. [...] a militarização urbana funciona como mecanismo de guetização da população excluída economicamente". Além de criar perante toda a sociedade e o próprio Estado e o Sistema de Justiça, um "estigma territorial impregnado, fortemente atrelado aos residentes desses bairros de exílio socioeconômico", o que "acrescenta o seu fardo à vergonha da pobreza e ao preconceito" (WACQUANT, 2005, p.195, grifos do autor).

No discurso oficial do Estado, se colocou como 
um dos objetivos principais da ocupação dos territórios dominados pelo tráfico de drogas como forma de pacificar tais localidades.

O fato é que as UPPs surgem como estratégia político-militar de ocupação e controle de localidades empobrecidas e, em grande medida, abandonadas pelo Estado. [...] Inicialmente ganhou apoio popular até mesmo dos moradores das localidades ocupadas. A expectativa de que, junto com a segurança, outros serviços públicos também se voltariam para essas localidades provocou um entusiasmo inicial, que logo foi substituído pela indignação dos moradores, ao perceber que estariam sujeitos a um ostensivo e violento controle policial, sem outro tipo de prestação social posterior (PASTANA, 2019, p.179).

Ante ao exposto, pode se apresentar o conceito de "periferias como campos de concentração a céu aberto", modalidade de controle que age por meio de dispositivos cujo objetivo é manter os habitantes das áreas em questão seus territórios sob o rígido controle do Estado.

Versa Augusto (2010,p.177), que tal controle

opera para

[...] imobilizar as pessoas tidas como carentes ou vulneráveis, [...] uma política do campo de concentração a céu aberto como investimento ininterrupto em manter determinada parte da população quieta e feliz. As pessoas que habitam essa região se veem enredadas em uma série de programas, aparelhos e políticas sociais que a todo momento registram, monitoram, permitem, recusam, direcionam, redimensionam a circulação em um espaço delimitado e móvel. Como anota Passetti: “Aparece, então, uma nova diagramação da ocupação do espaço das cidades, em que políticas de tolerância zero e de penas alternativas se combinam, ampliando o número de pobres e miseráveis visados, capturados e controlados, compondo uma escala mais ou menos rígida de punições, deixando inalterados a cifra negra e os dispositivos de seletividade. Consolida-se uma nova prática do confinamento a céu aberto, e o sistema penal mais uma vez se amplia dilatando os muros" (apud Passetti: 2006, p.94).

Tentamos explicitar aqui inúmeras maneiras pelas quais o estado Punitivo atua na segregação social e territorial das classes populares urbanas, denotando sua real intenção de segregação e monitoramento. A continuação abordaremos acerca do sistema carcerário brasileiro.

\section{SISTEMA CARCERÁRIO NACIONAL DOS MARGINALIZADOS}

Segundo Abramovay (2010, p.9), "da metade dos anos 1975 até os dias de hoje, a prisão se tornou o grande instrumento de política criminal no mundo todo".

Como já explicitado, vivemos uma virada punitiva sem precedentes no mundo ocidental. Segundo Wacquant (2001, p.7)

[...] a penalidade neoliberal apresenta o seguinte paradoxo: pretende remediar com "mais Estado" policial e penitenciário o "menos Estado" econômico e social que é a própria causa da escalada generalizada da insegurança objetiva e subjetiva em todos os países.

Ao analisar a situação brasileira Silva e Pastana (2017, p.381) asseveram que

[...] as políticas criminais, assim como os mecanismos punitivos transfiguram-se mais austeros atrelados a altos índices de criminalização e encarceramento das massas miseráveis que pouco podem contribuir com a insólita ordem econômica.

Infere-se que para se ter o entendimento sobre o cárcere nacional, é necessário analisar os dados do INFOPEN, o Levantamento Nacional de Informações Penitenciárias Atualização - Junho de 2017 (BRASIL, 2019), relatório oficial realizado pelo DEPEN (Departamento Penitenciário Nacional) que é órgão encarregado das informações referentes aos presos do nosso sistema prisional nacional.

Segundo os dados do INFOPEN mais recentes, há 726.354 pessoas privadas de liberdade no Brasil, sendo que só existem 423.242 vagas oferecidas pelo Estado. Tal dado que demonstra uma taxa de ocupação prisional extremamente preocupante, visto que possuímos um déficit de 303.112 vagas, gerando as problemáticas de superlotação do cárcere, com uma taxa de ocupação de $171,62 \%$.

Em relação aos presos por tipo de regime e natureza da prisão, os dados apresentados pelo relatório são os seguintes: " $43,57 \%$ das pessoas presas no Brasil são presos sentenciados em regime fechado, seguido de $33,29 \%$ composta por presos provisórios, ou seja, sem condenação e $16,72 \%$ presos em regime semiaberto" (BRASIL, 2019). 


\section{V.10 N.1 (2022) ISSN: $2317-434 X$}

No que concerne à etnia/cor os dados apontam que $63,6 \%$ da população privada de liberdade é preta ou parda. Sendo o índice de população branca, 35,4\% (BRASIL, 2019). O que mostra que o encarcerado brasileiro tem uma cor predominante. Os dados referentes à escolaridade são preocupantes: $60,6 \%$ dos privados de liberdade possuem até o Ensino Fundamental Incompleto e $88,8 \%$ não possuem o ensino médio completo.

Quanto aos dados referentes aos tipos penais que lideram o encarceramento no Brasil, a análise demonstrará quais os bens jurídicos mais tutelados pelo Estado Brasileiro. De acordo com os dados temos dois grupos majoritários que contemplam a maior parte das condenações: os Crimes contra o patrimônio com 234.866 condenados seguido pelos crimes relacionados ao tráfico de drogas com 156.749 condenados. Os dois grupos juntos totalizam aproximadamente $75,3 \%$ dos tipos penais cometidos pelos encarcerados no Brasil (BRASIL, 2019). Deste modo, concluí-seque a grande maioria da população penal brasileira, é negra, com baixíssima escolaridade, jovem e cometeu ou delitos conta o patrimônio ou delitos referentes ao tráfico de drogas.

\section{CONSIDERAÇÕES FINAIS}

Ao desfecho da pesquisa se almeja uma ponderada compreensão e visibilização voltada aos leitores e aos demais pesquisadores sobre o estudo acerca do estado punitivo e a criminalização carcerária com enfoque na segregação social, desta forma trazendo ao debate preocupações sobre este tema e suas consequências nas políticas públicas sociais, que vão desde uma ruptura na sociedade através da segregação racial e socioespacial, gerando uma errônea distribuição de recursos econômicos, até um crescente aumento na taxa de violência e criminalidade, fenômenos que refletem negativamente na esfera jurídica, acarretando uma saturação do ordenamento jurídico para a resolução de conflitos resultantes de problemáticas sociais que deveriam ser atendidas através de outras medidas, sejam elas sociais educacionais ou políticas.

Portanto a pesquisa em questão, busca uma maior visibilidade sobre este tema, em todas as áreas, não se restringindo apenas ao aspecto jurídico, mas sim tendo a mesma como base cientifica para novas iniciativas de pesquisas na seara interdisciplinar.

Trata-se de uma temática bastante complexa, que se requer, para uma determinação cabal desse fenômeno, um maior acesso a dados governamentais ainda indisponíveis ou de difícil acesso. Uma vez que o INFOPEN fez um novo levantamento da população carcerária no ano de 2020, entretanto, tais novos dados ainda não estão disponíveis, sendo tal comparação feita com os últimos dados divulgados, desta forma, acredita-se ser possível traçar de alguma maneira essas novas comparações.

O Estado brasileiro, como revela este trabalho, age de forma contraria a diversos direitos fundamentais da sua população, cujos rescaldos implicam que se anulam de maneira diuturna esses direitos humanos fundamentais aos sectores e classes sócias menos favorecidas. Primeiramente, por não serem abarcadas por políticas públicas de saneamento, energia, educação, cultura, saúde e moradia em seus bairros, recebendo do poder estatal apenas sua força coercitiva na forma do monitoramento constante de suas vidas pelas forças de repressão que exercem o controle social repressivo em representação do Estado. Em um segundo momento, ao tornarem-se os principais alvos do sistema de justiça, inundam os porões de nossos cárceres com as populações majoritárias de nossos precários centros urbanos. Constrói-se dessa maneira, uma narrativa de permanentes violações que se inicia nas periferias e terminam nas prisões.

\section{REFERÊNCIAS}

ABRAMOVAY, Pedro Vieira. O grande encarceramento como produto da ideologia (neo) liberal. In: ABRAMOVAY, Pedro Vieira; BATISTA, Vera Malaguti (Orgs.). Depois

grande encarceramento: seminário. 1.reimp. Rio de Janeiro: Revan, 2015. p.9-27.

Áreas urbanizadas do Brasil: 2015 / IBGE, Coordenação de Geografia. - Rio de Janeiro: IBGE, 2017.
AUGUSTO, Acácio. Para além da prisão-prédio: as periferias como campos de concentração a céu aberto. In: ABRAMOVAY, Pedro Vieira; BATISTA, Vera Malaguti (Orgs.). Depois do grande encarceramento: seminário. 1.reimp. Rio de Janeiro: Revan, 2015. p.175-181.

BRASIL.Levantamento nacional de informações penitenciárias, atualização junho de 2017. Brasília: Ministério da Justiça e Segurança Pública; Departamento Penitenciário Nacional, 2019. 


\section{V.10 N.1 (2022) ISSN: 2317-434X}

COELHO, Edihermes. Direito Penal - Parte Geral. 3.ed. Belo Horizonte: Editora Del Rey, 2016

GARLAND, David. A Cultura do controle: crime e ordem social na sociedade contemporânea. Rio de Janeiro: Revan, 2008

GIL, Antonio Carlos. Métodos e Técnicas de Pesquisa Social. 6. ed. São Paulo: Atlas, 2008.

STRECK, Lenio Luiz. Crime e sociedade estamental no Brasil: De como la ley es como la serpiente; solo pica a los descalzos. Cadernos IHU ideias, São Leopoldo, ano 10, n.178, 2012.

MENEZES, Catarino de Souza. A União Estável no Novo Código Civil e o Retrocesso Protetivo nos Direitos Sucessórios dos companheiros. Mato Grosso do Sul, 2008

NUCCI, Guilherme de Souza. Manual de Direito Penal. 10.ed. Rio de Janeiro: Forense, 2014.

PASTANA, Débora Reginaos contornos do estado punitivo no brasil.Perspectivas, São Paulo, v. 31, p. 2946, jan./jun. 2007

PASTANA, Débora Regina. Justiça penal no Brasil contemporâneo: discurso democrático, prática autoritária. São Paulo: Ed. da UNESP, 2009.

PASTANA, Débora Regina. Política e Punição na América Latina: uma análise comparativa acerca da consolidação do estado punitivo no Brasil e na Argentina. Rio de Janeiro: Revan, 2019

SAllA, F.; GAUTO, M.; ALVAREZ, M. C. A contribuição de David Garland: a sociologia da punição. Tempo Social, São Paulo, v.18, n.1, p.239-350, jun. 2006.

VERGARA, S.C. Projetos e relatórios de pesquisa em administração. 10.ed. São Paulo: Atlas, 2009.

VILLAÇA, Flávio. Espaço intra-urbano no Brasil. São Paulo: Studio Nobel: FAPESP: Lincoln Institute, 2001.

WACQUANT, Loïc. Punir os Pobres: A nova gestão da miséria nos Estados Unidos. 3.ed. Rio de Janeiro: Revan, 2003. (A Onda Punitiva)

WACQUANT, L. As prisões da miséria. Rio de Janeiro: J. Zahar, 2001

ZAFFARONI, Eugenio Raúl; PIERANGELI, José Henrique. Manual de direito penal brasileiro. 4.ed. São Paulo: Revista dos Tribunais, 2004. 